\title{
Free Sugars Intake among Chinese Adolescents and Its Association with Dental Caries: A Cross-Sectional Study
}

\author{
Qiping Yang ${ }^{\dagger}$, Yue Xi ${ }^{\dagger}{ }^{\circ}$, Hanmei Liu, Jing Luo, Yufeng Ouyang, Minghui Sun, Cuiting Yong, Caihong Xiang \\ and Qian Lin *(1)
}

check for

updates

Citation: Yang, Q.; Xi, Y.; Liu, H.; Luo, J.; Ouyang, Y.; Sun, M.; Yong, C.; Xiang, C.; Lin, Q. Free Sugars Intake among Chinese Adolescents and Its Association with Dental Caries: A Cross-Sectional Study. Nutrients 2021, 13, 765. https://doi.org/10.3390/ nu13030765

Academic Editor: Emily Sonestedt

Received: 30 January 2021

Accepted: 23 February 2021

Published: 26 February 2021

Publisher's Note: MDPI stays neutral with regard to jurisdictional claims in published maps and institutional affiliations.

Copyright: (c) 2021 by the authors. Licensee MDPI, Basel, Switzerland. This article is an open access article distributed under the terms and conditions of the Creative Commons Attribution (CC BY) license (https:// creativecommons.org/licenses/by/ $4.0 /)$.
Department of Nutrition Science and Food Hygiene, Xiangya School of Public Health, Central South University, 110 Xiangya Rd, Changsha 410078, China; yangqiping12@csu.edu.cn (Q.Y.); xiyue0404@csu.edu.cn (Y.X.); hanmeiliu@csu.edu.cn (H.L.); luojing2546@csu.edu.cn (J.L.); oyyf0102@csu.edu.cn (Y.O.); sun.1234@csu.edu.cn (M.S.); yongcuiting@csu.edu.cn (C.Y.); xch0622@csu.edu.cn (C.X.)

* Correspondence: linqian@csu.edu.cn; Tel.: +86-1387-482-0173

+ These authors are co-first authors contributed equally to this paper.

\begin{abstract}
This study aims to estimate the free sugars intake, identify the primary food sources of free sugars, and explore the relationship between free sugars intake and dental caries among Chinese adolescents. This cross-sectional study included 1517 middle-school students aged 12-14 years in Changsha city, China. Adolescents completed a 12-item Food Frequency Questionnaire (FFQ) and oral health assessment. The students' dental caries experience was available as DMFT score (number of decayed, missing, and filled permanent teeth). Statistical analyses included the Mann-Whitney test, Kruskal-Wallis test, Chi-square test, and binary logistic regression model. The average intake of free sugars was $53.1 \mathrm{~g} / \mathrm{d}$ in adolescents, and $43.2 \%$ of the students consumed more than $50 \mathrm{~g}$ of free sugars daily. The primary contributor to free sugars was sugar-sweetened beverages (SSBs). Age, boarders, and high family income were risk factors for excessive free sugars intake $(p<0.05)$, and increased free sugars intake was a risk factor for dental caries (odds ratio, $\mathrm{OR}=1.446,95 \%$ confidence interval: 1.138-1.839). Both the free sugars intake and dental caries prevalence in Chinese adolescents were high. Targeted interventions are urgently needed to address the excessive consumption of free sugars and improve Chinese adolescents' oral health.
\end{abstract}

Keywords: adolescent; dietary sugars; sugar-sweetened beverages; dental caries; oral health

\section{Introduction}

Dental caries is one of the most prevalent oral conditions worldwide, which affects about $35.3 \%$ of the global population at all ages [1]. Tooth decays begin for many people from early stages without symptoms and continue at advanced settings causing pain, anxiety, functional limitation (including low school attendance and performance in children), and social handicap through tooth loss [2]. Not only does caries harm individuals' health, but it results in a health-related economic burden. It has been estimated that 298 billion USD was spent on direct costs associated with dental caries, accounting for about $67.4 \%$ of the total financial outlay globally in 2010 [3]. In 2017, dental caries affected 621 million children worldwide [3], with a $20.6 \%$ rise during a decade [4]; as for China, the prevalence of permanent teeth caries among 12-year-olds increased by 7.8\% from 2007 to 2017 [5]. This increase, at home and abroad, alarmed us to pay more attention to dental caries prevention. Dental caries is mostly preventable through cost-effective and straightforward population-wide and individual interventions [2].

Dental caries is significantly moderated by age, sex, social determinants (income and education), health-related behaviors (smoking, diet, alcohol consumption, and healthcare attendance), and water fluoridation [6]. Sugars are the essential factor for dental caries [7]; a decayed tooth develops when bacteria in the mouth metabolize sugars to produce acid that demineralizes the tooth's hard tissues. As defined by the World Health Organization 
(WHO) in 2015, free sugars include monosaccharides and disaccharides added to foods and beverages by the manufacturer, cook, consumer, and sugars naturally present in honey syrups, fruit juices, and fruit juice concentrates. Free sugars contribute to diets' overall energy density and promote a positive energy balance $[8,9]$. Due to the association between free sugars intake and risk of dental caries [10], the increasing free sugars intake, especially in the form of sugar-sweetened beverages (SSBs) and sweetened foods, is of concern among children [11], adolescents [12,13], and adults [14]. Since the sweet preference is higher in adolescence than in adulthood $[15,16]$, this stage is particularly vulnerable to the health consequences of high sugars intake. In several foreign studies [17-20], a large proportion of adolescents exceeded the recommendations on free sugars consumption. Such a high sugars intake may be of relevance, as adolescence is suggested to be a "critical period" for developing various diseases in later life [21,22], and dietary patterns have been shown to track into adulthood. However, the relevant studies conducted on Chinese adolescents are limited, and they mostly focused on the intake frequency of sugar-sweetened beverages [23-25] but ignored the amount of total free sugars consumption.

To date, no studies have explored the association of free sugar intake with dental caries among Chinese adolescents, and the amount and source of their free sugars' consumption is unclear. Therefore, this study aims to assess the daily intake of free sugars as well as identify the food sources of free sugars and the association between free sugars' consumption and dental caries in Chinese adolescents aged 12-14 years. We hypothesized that the risk of dental caries is positively associated with the consumption of free sugars. This study may be helpful for developing health strategies concerning free sugar intake and oral health for Chinese adolescents.

\section{Materials and Methods}

\subsection{Ethical Approval}

The study was approved by the Ethics Review Committee of the Xiangya School of Public Health, Central South University (XYGW-2019-025). Before the investigation, written informed consent from parents or caregivers was obtained, and all information was kept confidential.

\subsection{Study Design and Participants}

This cross-sectional study was conducted from March to July 2019 in Changsha, the capital city of Hunan Province in south-central China. Two-stage stratified random cluster sampling was used to select ten middle schools from five districts (Yuhua District, Tianxin District, Furong District, Kaifu District, and Yuelu District) in Changsha city. In each section, two middle schools were selected randomly. Recruitment was targeted at 7th and 8th-grade students. The inclusion criteria for selection are as follows: (1) schools that enrolled more than 500 students and agreed to participate in the study, (2) parents' or caregivers' information consented and agreed to participate. Exclusion criteria were those students who could not read or write and thus complete the questionnaire.

Before the investigation, we submitted the protocol to the local Education Bureau for permission to conduct this investigation. Under the education bureau's assistance, we contacted leaders of the selected schools and delivered consent forms to students. The eligible students were enrolled if their parents or caregivers signed informed consent. A total of 1628 students participated in this study; of these, 1517 students finished the questionnaire and were included in the final analyses (participate rate: $93.2 \%$ ).

\subsection{Measures}

The survey included an online questionnaire, anthropometric measurements, and dental caries assessment. Teachers in the selected schools organized all the processes. 


\subsubsection{Questionnaire Survey}

Uniformly trained research assistants guided the students to complete the online questionnaire in the school computer room. The online questionnaire was delivered via The Questionnaire Star, which is a tool used to develop electronic questionnaires. Each questionnaire had a unique linkage. Along with demographics information, students' food consumption and oral health-related behaviors were collected.

- Students' demographic information: including students' sex, age, ethnicity, sibling status (the only child or not), family monthly income, and parents' education attainment.

- Food consumption: A 12-item Food Frequency Questionnaire (FFQ) was used to assess food consumption during the last week. This FFQ consisted of cereals and wheat, vegetables (leafy vegetables, melon vegetables, and root or stem vegetables), fruits, soybeans and its products, dairy and its products, meat, poultry, fish and shrimp, eggs, and SSBs and sweetened foods. The 6-category response options of intake frequencies ranged from "once a month or less" to "twice or more a day".

- SSBs and sweetened foods consumption: The average intake of SSBs and sweetened foods were collected via the FFQ mentioned above. The food groups were set according to database of free sugars content from Chinese Center for Disease Control and Prevention (China CDC) (shown in Table A1). Carbonated drinks, vegetable protein drinks, juice or juice drink, tea drinks, sports drinks, and bubble tea were included in SSBs. Sweetened foods included cakes, desserts, confectionery (chocolate, Snickers and Maltesers, etc.), and preserved fruits (dried fruits and candied fruits). Honey and flavored milk/yogurt were also included as sources of free sugars. The response options of the average intake of SSBs and sugary foods included " $100 \mathrm{~mL} / \mathrm{time}, 200$ $\mathrm{mL} /$ time, $300 \mathrm{~mL} /$ time, $400 \mathrm{~mL} /$ time and $500 \mathrm{~mL} /$ time" and " $25 \mathrm{~g} /$ time, $50 \mathrm{~g} /$ time, $75 \mathrm{~g} /$ time, $100 \mathrm{~g} /$ time, $150 \mathrm{~g} /$ time and $200 \mathrm{~g} /$ time"$^{\prime \prime}$, respectively.

- Oral health-related behaviors: Oral health-related behaviors were collected by five selfdesigned questions, including: (1) Do you have the dental health education lectures in your school? (2) How often do you brush your teeth every day? (with the response option of "1 time/day or less" and "2 times/day or more") (3) Will you brush your teeth after intake of SSBs and/or sweetened foods? (4) Do you often use dental floss or mouthwash? (5) Do you have a regular dental visiting?

\subsubsection{Anthropometric Measurements}

Each participant's height and weight were measured by uniformly trained research assistants using the standard height meter and TANITA human body composition analyzer BC-W02C (Guangdong Food and Drug Administration (prospective), No 2210704, 2014). Body mass index (BMI) was calculated via dividing body weight $(\mathrm{kg})$ by height squared $\left(\mathrm{m}^{2}\right)$. According to age- and sex-specific BMI cut-off values for Chinese children and adolescents (6-18 years old) [26], participants were classified as in either the normal or overweight/obese group (shown in Table A2).

\subsubsection{Dental Caries Assessment}

Dental caries conditions were evaluated and recorded by two professional dentists. Students lined up in a classroom. The dentists assessed their oral hygiene status one by one using a disposable dental mirror with a light-emitting diode (LED) light and ball-end Community Periodontal Index (CPI) probe. Food debris was gently removed to avoid the under-recording of dental caries. The diagnostic criteria for dental caries followed the recommendation from the WHO [27].

- Dental caries experience was measured via the decayed-missing-filled teeth (DMFT) index. DMFT is a cumulative measurement by summing the number of decayed (D), missing (M), and filled (F) teeth. A tooth that decayed but has not been filled would be recorded as decayed (D). When a tooth was extracted due to caries, it would be recorded as missing $(\mathrm{M})$. A tooth recorded as filled $(\mathrm{F})$ when it was permanently filled without caries. 
- Dental caries prevalence, the proportion of the students with the DMFT $\geq 1$, was set as a dichotomous dependent variable. After the dental examination, an individual report of oral hygiene was delivered to each student.

\subsection{Free Sugars Intake Assessment}

The primary sources of free sugars were derived from SSBs and sweetened foods included in the 12-item FFQ mentioned above. The response options of FFQ were converted to daily consumption frequencies as follows: $0=$ "once a month or less", 0.14 times $/$ day = "once a week", 0.36 times / day = "2-3 times a week", 0.64 times/day = "4-5 times a week" and 2 times/day = " 2 times/day or more".

The following Formula (1) calculated the individual's estimated daily intake of free sugars:

$$
\mathrm{Z}=\mathrm{A}\left(\mathrm{f}_{1}\right) \times \frac{\mathrm{A}\left(i_{1}\right)}{7} \times \mathrm{c}_{1}+\mathrm{B}\left(\mathrm{f}_{2}\right) \times \frac{\mathrm{B}\left(i_{2}\right)}{7} \times \mathrm{c}_{2}+\ldots+\mathrm{X}\left(\mathrm{f}_{\mathrm{n}}\right) \times \frac{\mathrm{X}\left(i_{\mathrm{n}}\right)}{7} \times \mathrm{c}_{\mathrm{n}} .
$$

Daily consumption of free sugars $(\mathrm{Z}, \mathrm{g} / \mathrm{d})$; food types $(\mathrm{A}, \mathrm{B}, \cdots, \mathrm{X})$; frequency (f, times/d); intake of each time ( $i, \mathrm{~g}$ or $\mathrm{mL})$; and free sugars content were from the China CDC database (c, g/100 g or mL/100 mL. Shown in Table A1), and $\mathrm{n}$ is a natural number. For some certain foods absent from the database, the average sugar content of such types of foods was used as a substitution. According to the recommendation of the latest China's dietary guidelines [28], students were divided into low-sugar consumption groups, medium-sugar consumption groups, and high-sugar consumption groups ( $25 \mathrm{~g}$ and $50 \mathrm{~g}$ as the cut-off values, respectively).

\subsection{Statistical Analyses}

EpiData3.0 software (The Epi Data Association, Odense, Denmark) was used for data entry, the IBM SPSS24.0 software (IBM Corp., Armonk, NY, USA) was used for data analyses, and the figure was presented by GraphPad Prism7.0 (GraphPad Software, Inc., San Diego, CA, USA). Descriptive information was presented as percentage or the mean with standard deviation. Chi-squared test and non-parametric tests were used to analyze general demographic data for different classification variables or continuous variables. Binary logistic regression analysis was used to analyze the association between free sugars intake and dental caries, adjusted by sex, age, BMI status, domicile place, and regular dental visiting. Significant levels were set at $p<0.05$.

\section{Results}

\subsection{Characteristics of Participants}

A total of 1517 students in 7th and 8th grades from ten schools participated in this study (Table 1). Of these, 53.3\% were boys. Ages ranged from 12 to 14 years old, and most students were 12 years old $(47.3 \%)$. Only children accounted for $44.7 \%$ of the total adolescents. Most of the students $(92.2 \%)$ lived in their own homes during the school years. Overall, there were $27.3 \%$ of the students who were overweight/obese. More than half of the students' parents $(65.2 \%)$ had acquired high school education or above. There were $39.8 \%$ of the students whose household incomes were lower than 5000 RMB monthly. The average intake of free sugars was $53.1 \mathrm{~g} / \mathrm{d}$ in the present study. The higher the students grades, the more the free sugars intake $(56.3 \mathrm{~g} / \mathrm{d}$ vs. $50.2 \mathrm{~g} / \mathrm{d}, p<0.05)$. The consumption of free sugars in boarding students was significantly higher than that of the students who lived in their own homes during the school year $(62.4 \mathrm{~g} / \mathrm{d}$ vs. $52.4 \mathrm{~g} / \mathrm{d}, p<0.05)$. 
Table 1. Characteristics of the adolescents by outcome variables $(n=1517)$.

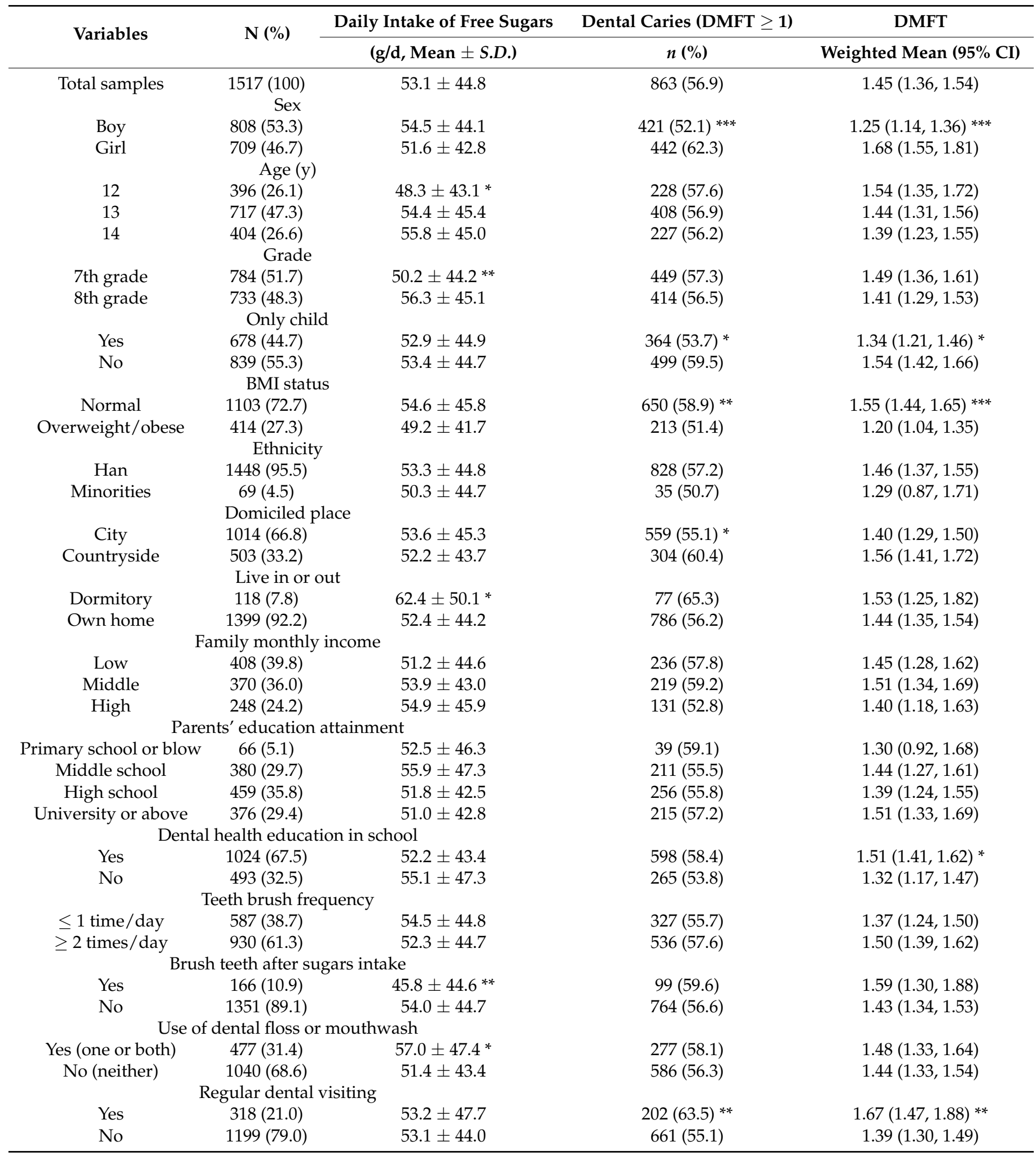

${ }^{*} p<0.05,{ }^{* *} p<0.01,{ }^{* * *} p<0.001$; compared by Mann-Whitney U test, Kruskal-Wallis test or Chi-square test. DMFT: decayed, missing, and filled permanent teeth. BMI status: grouped by age- and sex- specific BMI cut-off values. Family monthly income: low $(<5000 R M B)$, middle (5000-9000 RMB), high (>9000 RMB). RMB: Renminbi, Chinese official coupons, 1 RMB $\approx 0.16$ USD.

The prevalence of dental caries was $56.9 \%$, and the weighted mean DMFT was 1.45 (95\% CI: $1.36-1.54)$. More girls than boys had dental caries $(62.3 \%$ vs. $52.1 \%, p<0.05)$, and the prevalence of dental caries among the only children was lower than that of those 
with siblings (53.7\% vs. $59.5 \%, p<0.05$ ). Compared to the students with normal BMI status, those who were overweight/obese had a lower prevalence of dental caries ( $58.9 \%$ vs. $51.4 \%, p<0.05)$, as well as a lower risk of dental caries experiences (1.55 vs. 1.20, $p<0.05)$. More adolescents from the rural area than the urban area had a higher prevalence of dental caries $(55.1 \%$ vs. $60.4 \%, p<0.05)$. The students who visited dentists regularly had both a higher prevalence of dental caries $(63.5 \%$ vs. $55.1 \%, p<0.05)$ and risk of dental caries experiences ( 1.67 vs. $1.39, p<0.05)$.

\subsection{Free Sugars Intake and Its Sources among Adolescents}

According to The Dietary Guidelines for Chinese Residents (2016), the appropriate daily intake of added sugars for adults should not exceed $50 \mathrm{~g}$, and it would be preferable if intake was below $25 \mathrm{~g}$. In our study, only $30.6 \%$ of adolescents consumed free sugars lower than $25 \mathrm{~g} / \mathrm{d}$, and $43.2 \%$ of adolescents had an excessive intake of free sugars higher than the recommended maximum level (Table 1). The primary source of free sugars in the adolescents was SSBs, which provided $54.2 \%$ for free sugars' daily intake (Figure 1). Flavored milk/yogurt and confectionery followed, with the contribution of $14.9 \%$ and $13.0 \%$, respectively, which were followed by preserved fruits, cakes or desserts, and honey. For sex, boys consumed more SSBs than girls did, while girls' intake of confections, flavored milk/yogurt, preserved fruits, and cakes and desserts were all higher than boys' $\left(p_{\text {-all }}<0.05\right)$.

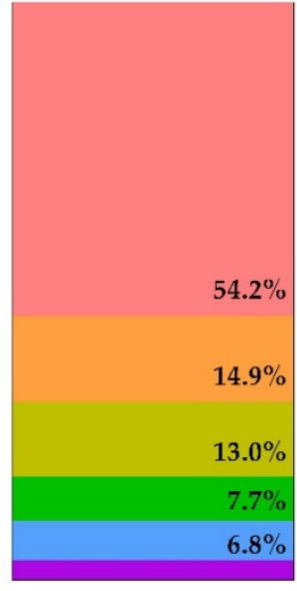

Total

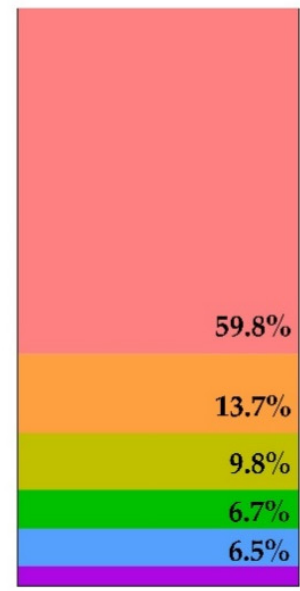

Boys

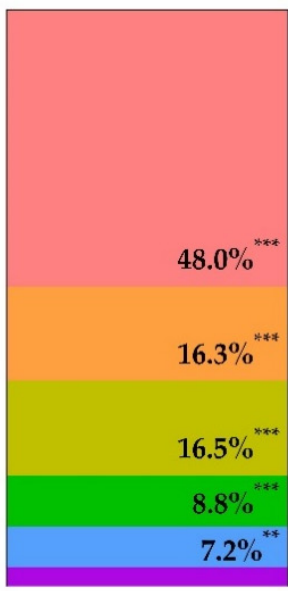

Girls

Proportion of total free sugars

Figure 1. Sources of free sugars for adolescents by sex (the proportion of total free sugars, $\%$ ). ${ }^{*} p<0.05,{ }^{* *} p<0.01$, *** $p<0.001$; compared boys with girls by Mann-Whitney U test. Sugar-sweetened beverages (SSBs) include sodas, vegetable protein beverages, juice or juice drinks, tea drinks, sports drinks, and bubble tea.

\subsection{Association between Free Sugars Consumption and Dental Caries}

In the present study, $56.9 \%$ of the students had dental caries. Adolescents with decayed teeth consumed more free sugars than those without dental caries $(56.9 \mathrm{~g} / \mathrm{d}$ vs. $48.2 \mathrm{~g} / \mathrm{d}, p<0.05)$. For specific food groups, the differences between the adolescents with and without dental caries were similar to the consumption of free sugars in different sex (Table 2) and weekly frequencies (Table A3). 
Table 2. The average free sugars intake from food groups by DMFT score (number of decayed, missing, and filled permanent teeth) (mean \pm S.D., g/d).

\begin{tabular}{cccc}
\hline The average intake & $\begin{array}{c}\text { Total } \\
(\boldsymbol{n}=\mathbf{1 5 1 7})\end{array}$ & $\begin{array}{c}\text { DMFT }=\mathbf{0} \\
(\boldsymbol{n}=\mathbf{6 5 4})\end{array}$ & $\begin{array}{c}\text { DMFT } \geq \mathbf{1} \\
(\boldsymbol{n}=\mathbf{8 6 3})\end{array}$ \\
\hline $\begin{array}{c}\text { Food Groups } \\
\text { SSBs }{ }^{* *}\end{array}$ & $33.9 \pm 40.6$ & $30.6 \pm 38.9$ & $36.5 \pm 41.6$ \\
Confections ${ }^{* *}$ & $10.1 \pm 22.8$ & $8.3 \pm 19.2$ & $11.4 \pm 25.2$ \\
Flavored milk/yogurt ${ }^{* *}$ & $9.1 \pm 15.2$ & $8.1 \pm 14.6$ & $9.9 \pm 15.6$ \\
Preserved fruits & $6.3 \pm 18.3$ & $5.6 \pm 18.4$ & $6.8 \pm 18.2$ \\
Cakes or desserts & $3.8 \pm 7.9$ & $3.3 \pm 6.6$ & $4.1 \pm 8.8$ \\
$\quad$ Honey & $2.5 \pm 9.7$ & $1.8 \pm 5.8$ & $2.9 \pm 11.8$ \\
Total ${ }^{* *}$ & $53.1 \pm 44.7$ & $48.2 \pm 41.1$ & $56.9 \pm 47.0$ \\
\hline${ }^{*} p<0.05,{ }^{* *} p<0.01,{ }^{* * *} p<0.001 ;$ comparison between DMFT $=0$ group and DMFT $\geq 1$ group by Mann-Whitney \\
U test. SSBs include sodas, vegetable protein beverages, juice or juice drinks, tea drinks, sports drinks, and bubble \\
tea.
\end{tabular}

The binary logistic regression model was also conducted to evaluate the association between dental caries as the dependent variable (DMFT $=0$ as the reference) and free sugars intake (Table 3). Our results found that the students who consume free sugars more than $50 \mathrm{~g} / \mathrm{d}$ were significantly more likely to have dental caries (crude OR $=1.446,95 \%$ CI: 1.138 $1.839, p<0.05)$. These associations remained after the adjustment. For different sources of free sugars, a higher intake of SSBs (adjusted OR $=1.005,95 \%$ CI: 1.002-1.007, $p<0.05$ ), confections (adjusted OR $=1.005,95 \%$ CI: 1.000-1.010, $p<0.05$ ), flavored milk/yogurt (adjusted OR $=1.007,95 \%$ CI: 1.000-1.014, $p<0.05$ ) and honey (adjusted OR $=1.015,95 \%$ CI: $1.001-1.029, p<0.05)$ were risk factors of suffering dental caries. Meanwhile, there were no associations between preserved fruits, cakes and desserts, and dental caries.

Table 3. Binary logistic regression models of association between free sugar intake and dental caries experience among adolescents (DMFT $=0$ as the reference).

\begin{tabular}{|c|c|c|}
\hline Variables & Crude OR $(95 \%$ CI) & Adjusted OR (95\% CI) \\
\hline \multicolumn{3}{|l|}{ Free sugars intake (vs. Low) } \\
\hline Middle $(25 \sim 50 \mathrm{~g} / \mathrm{d})$ & $1.294(0.988,1.695)$ & $1.248(0.949,1.641)$ \\
\hline $\operatorname{High}(>50 \mathrm{~g} / \mathrm{d})$ & $1.446(1.138,1.839)^{* *}$ & $1.463(1.146,1.867) * *$ \\
\hline \multicolumn{3}{|l|}{ Sources of Free Sugars } \\
\hline SSBs & $1.004(1.001,1.006) * *$ & $1.005(1.002,1.007) * *$ \\
\hline Confections & $1.007(1.002,1.012)$ * & $1.005(1.000,1.010)$ * \\
\hline Flavored milk/yogurt & $1.008(1.001,1.015) *$ & $1.007(1.000,1.014)$ * \\
\hline Preserved fruits & $1.004(0.998,1.010)$ & $1.003(0.997,1.009)$ \\
\hline Cakes or Desserts & $1.014(1.000,1.028)$ & $1.013(0.999,1.027)$ \\
\hline Honey & $1.014(1.001,1.028)$ * & $1.015(1.001,1.029)$ * \\
\hline
\end{tabular}

\section{Discussion}

Our study indicates that 12-14-year-old Chinese adolescents have a high consumption of free sugars, which are associated with the prevalence of dental caries. Adolescents who are female, more senior, and living in the dormitory during school years tend to consume more SSBs and sugary foods and thus might have a higher risk of dental caries. Given that the information on the consumption of free sugars in China is insufficient, this study would guide sugar intake reduction and dental caries prevention in adolescents.

In our results, the free sugars intake of adolescents was $53.1 \mathrm{~g} / \mathrm{d}$, which is lower than that in U.S. adolescents with $94.0 \mathrm{~g} / \mathrm{d}$ [19], Latin American countries from 58.2 to $106.9 \mathrm{~g} / \mathrm{d}$ [20], and in European countries with $110.1 \mathrm{~g} / \mathrm{d}$ [29]. This may be due to urbanization levels, local dietary habits, measuring and analytical methods of free sugars in different countries [30]. Studies on the consumption of free sugars in adolescents 
from China are limited. Compared with other age groups, the average intake of free sugars in adolescents is higher than that of adults who consumed sugary foods in China $(18.8 \mathrm{~g} / \mathrm{d})$ [31], and it is also higher than that of residents in Tianjin City with an intake of $24.1 \mathrm{~g} / \mathrm{d}$ [32]. Several studies suggested that the consumption of free sugars topped in adolescents [30,33], which was reflected by our findings that older students consumed more free sugars than 12-year-olds did. This could be explained by their immaturity in choosing their foods $[30,34]$, and largely by the influence of many factors such as living environments and the availability of sugary drinks [35-37]. It is also supported by our results that the boarders consumed more free sugars daily than day students. Overall, public health programs to lower sugar intake need to focus on this vulnerable population urgently.

We also found the main contributor to free sugars in adolescents was SSBs (54.2\%). Similar findings were observed in other countries [18,38-40]. However, in our study, the categories that followed SSBs were flavored milk/yogurt (14.9\%) and confectionery (13.0\%), which was slightly different from other studies. Among Australian adolescents, sugars and sweet spreads, cakes, biscuits, pastries, and batter-based products were the secondary sources of free sugars [39]. In Spain, except for SSBs, the major source of free sugars intake in children and adolescents were sugar and bakery and pastry items [41]. For Greek 10-12-year-old adolescents, sweets, sugared fruit juices, and chocolate milk were major contributors apart from SSBs [42]. This could be explained by regional disparities, such as related policy [43], economic level [34], food consumption habits [34], and variations of food composition [44]. In line with the previous studies, we also found that boys tend to drink more sugary drinks $[30,45,46]$, while girls prefer sugary foods; this could be because of adolescents' sweetness and food preference [15], physical activity [47], as well as pubertal desires for a slim body [46]. A reduction of SSBs consumption is urgently needed in adolescents. It is essential to improve schools' food environment by regulating the sale of beverages and foods that are high in free sugars [48].

Given China's thriving production and output of SSBs [49,50], the impact of excessive free sugars intake on adolescents' health should be of concern. Dental caries is one of the most known consequences of an excessive intake of free sugars. Our study presented that the prevalence of dental caries in adolescents was at a high level of $56.9 \%$, which was not only higher than the 34.5\% from the 4th National Oral Health Epidemiological Survey [5] but also higher than that of students in Jiangxi province and Zhejiang province $(25.8 \%$ and $44.0 \%$, respectively) [51,52]. According to the assessment criteria of DMFT from WHO [27], average caries (DMFT) in 12-year-olds ranged from 1.2 to 2.6 , representing a generally low level. Our study revealed that the mean caries (DMFT) of the adolescents was 1.45 (95\% CI 1.36-1.54), which was higher than the overall caries of 12-15-year-old teenagers in Jiangxi province (0.48) [51], Chongqing Province (0.99) [53], and the national level (1.04) [5]. However, it was lower than rural left-behind children aged 12 years old in Henan province with a DMFT of 1.75 [54]. Both the dental caries score (DMFT) and dental caries prevalence of female students were higher than those of male students, which was in accordance with previous findings $[51,52]$.

With Chinese characteristics, we found only children had a lower DMFT as well as the prevalence of dental caries. Compared with children with siblings, the only children are more likely to be well brought up and supervised [51]. However, we did not observe the association between low family income, low parental education attainments, and dental caries. It might be contrary to the major viewpoints that people with low socioeconomic status might have poor oral status [55] but could be explained by the universal coverage of medical insurance in China [56]. Furthermore, health education lectures held in school might decrease the impact of parental socioeconomic status on oral health. Rather than accelerating economic development, it is more important to disseminate health messages. Health professionals and teachers have a crucial role in such nutrition health education on sugars and health in school [7]. 
Apart from oral health practices, fluoride is another preventive factor for dental caries. Although the use of mouth rinses was considered, the use of fluoridated toothpaste or mouth rinses was not evaluated in our study. Some studies have found that even considering the use of fluoride, the effect of sugar intake on dental caries still exists [57,58]; these findings highlighted the need for low sugars intake throughout life, whether fluoride intake is optimum [59]. Above all, verifying the association between free sugars intakes and dental caries would be practical for policy makers in China to adopt multiple measures to reduce the free sugars intake in adolescents.

We did not observe the associations between BMI and free sugars intake among adolescents, which was different from other studies $[45,60,61]$. Individuals with overweight/obesity are more likely to underreport their consumption and provide socially desirable answers, particularly in adolescents [62]. Another probability for this result was that we could not adjust energy intake, while it is well known that excess energy intake plays a crucial role in weight gain [63]. This study found a negative association between BMI status and dental caries, which is in accordance with some research [64-66] but inconsistent with the majority [67-69]. Individuals, especially overweight or obese adolescents, tend to restrict their intake from high-fat and high-sugar foods [70], while lean, active individuals tend to select high-energy and high-sugar diets [71]; thus, low caries is associated with high BMI. Another explanation may be an increased consumption of high-fat diets, which is associated with weight gain positively, rather than caries [72].

The main strengths of our study are its sufficient sample size and strict quality control. The oral status was assessed and recorded by the professional dentists, and the weight status was measured by uniformly trained assistants, which improved the reliability of the anthropometric data. Moreover, the investigation tool was reliable, and participants had to complete it before submitting it to ensure the integrity of the questionnaire data.

However, there were several limitations. Firstly, the causal relationship between free sugars intake and dental caries could not be identified due to the cross-sectional study. For another, the uses of fluoridated toothpaste or mouth rinses among the participants could not be assessed in this study. Moreover, we used a semi-quantitative FFQ, which could not accurately reflect the intake of free sugars since the total energy intake could not be estimated and adjusted. In addition, some free sugars were not included, such as sucrose in homemade dishes, or the free sugars in some foods is unknown. Additionally, the study sample was from Changsha, the Hunan Province's capital city in central-south China. Therefore, the findings cannot be extrapolated to adolescents in rural or other parts of China, where the eating habits and dietary culture are different.

\section{Conclusions}

In addition to the excessive consumption of free sugars, the prevalence of dental caries in Chinese adolescents was relatively high. The primary source of free sugars for teenagers was sugar-sweetened beverages, and free sugars intake is associated with a high risk of dental caries. Promoting a healthy eating environment and restricting SSBs consumption would be important for addressing excessive intake of free sugars for adolescents. Future research should focus more on developing the free sugars database to estimate sugar intake conveniently. Simultaneously, a prospective study of a large population should be conducted to clarify the causal association between free sugars and dental caries or other diseases.

Author Contributions: Conceptualization and methodology, Q.L. and Q.Y.; software and validation, Q.Y.; formal analysis, Q.Y., and Y.X.; investigation, Q.Y., H.L., J.L., Y.O., M.S., Y.X., C.Y., and C.X.; resources, Q.L. and Q.Y.; data curation, Q.Y.; writing —original draft preparation, Q.Y., and Y.X.; writing-review and editing, Q.Y. and Y.X.; supervision, Q.L., and Q.Y.; project administration, Q.L., and Q.Y.; funding acquisition, Q.L., and Y.X. All authors interpreted the results and made a substantial contribution to the improvement of the manuscript. All authors have read and agreed to the published version of the manuscript. 
Funding: This study was supported by the Fundamental Research Funds for the Central Universities of Central South University [Grant number 2020zzts815].

Institutional Review Board Statement: The study was conducted according to the guidelines of the Declaration of Helsinki and approved by the Ethics Committee of the Xiangya School of Public Health, Central South University (XYGW-2019-025).

Informed Consent Statement: Informed consent was obtained from all students' parents or caregivers involved in the study.

Data Availability Statement: The data that support the findings of this study are not publicly available due to the data containing information that could compromise participant privacy but are available from the corresponding author on reasonable request.

Acknowledgments: We would like to thank the teachers and students from Xiangya Stomatological Hospital and Xiangya School of Public Health, Central South University, in Changsha, China, for their involvement in this investigation. We would appreciate the Changsha Education Bureau for their negotiation with middle schools. We are also grateful to teachers and leaders from the middle schools for their supports.

Conflicts of Interest: The authors declare no conflict of interest. The funders had no role in the design of the study; in the collection, analyses, or interpretation of data; in the writing of the manuscript, or in the decision to publish the results.

\section{Appendix A}

Table A1. Food item, quantity, and free sugars from Chinese Center for Disease Control and Prevention (China CDC).

\begin{tabular}{cccc}
\hline Food Descriptor & Quantity & Types & Free Sugars (g) \\
\hline Carbonated drinks & $100 \mathrm{~mL}$ & 9 & 9.79 \\
Bubble tea & $100 \mathrm{~mL}$ & 7 & 7.89 \\
Tea drinks & $100 \mathrm{~mL}$ & 6 & 4.31 \\
Juice or juice drinks & $100 \mathrm{~mL}$ & 21 & 10.47 \\
Vegetable protein beverages & $100 \mathrm{~mL}$ & 19 & 7.14 \\
Sports drinks & $100 \mathrm{~mL}$ & 6 & 8.22 \\
Flavored milk/yogurt & $100 \mathrm{~mL}$ & 29 & 12.28 \\
Biscuits, cakes & $100 \mathrm{~g}$ & 118 & 17.50 \\
Chocolate, confectionery & $100 \mathrm{~g}$ & 14 & 44.63 \\
Fruit preserves & $100 \mathrm{~g}$ & 12 & 55.04 \\
Honey & $100 \mathrm{~g}$ & 2 & 73.00 \\
\hline
\end{tabular}

\section{Appendix B}

Table A2. Age- and sex-specific BMI cut-off values for Chinese children and adolescents (6-18 years old, $\left.\mathrm{kg} / \mathrm{m}^{2}\right)$.

\begin{tabular}{ccccc}
\hline \multirow{2}{*}{ Age (Years) } & \multicolumn{2}{c}{ Boys } & \multicolumn{2}{c}{ Girls } \\
\cline { 2 - 5 } & Overweight & Obese & Overweight & Obese \\
\hline 6.0 & 16.4 & 17.7 & 16.2 & 17.5 \\
6.5 & 16.7 & 18.1 & 16.5 & 18.0 \\
7.0 & 17.0 & 18.7 & 16.8 & 18.5 \\
7.5 & 17.4 & 19.2 & 17.2 & 19.0 \\
8.0 & 17.8 & 19.7 & 17.6 & 19.4 \\
8.5 & 18.1 & 20.3 & 18.1 & 19.9 \\
9.0 & 18.5 & 20.8 & 18.5 & 20.4 \\
9.5 & 18.9 & 21.4 & 19.0 & 21.0 \\
10.0 & 19.2 & 21.9 & 19.5 & 21.5 \\
10.5 & 19.6 & 22.5 & 20.0 & 22.1 \\
11.0 & 19.9 & 23.0 & 20.5 & 22.7 \\
\hline
\end{tabular}


Table A2. Cont.

\begin{tabular}{ccccc}
\hline \multirow{2}{*}{ Age (Years) } & \multicolumn{2}{c}{ Boys } & \multicolumn{2}{c}{ Girls } \\
\cline { 2 - 5 } & Overweight & Obese & Overweight & Obese \\
\hline 11.5 & 20.3 & 23.6 & 21.1 & 23.3 \\
12.0 & 20.7 & 24.1 & 21.5 & 23.9 \\
12.5 & 21.0 & 24.7 & 21.9 & 24.5 \\
13.0 & 21.4 & 25.2 & 22.2 & 25.0 \\
13.5 & 21.9 & 25.7 & 22.6 & 25.6 \\
14.0 & 22.3 & 26.1 & 22.8 & 25.9 \\
14.5 & 22.6 & 26.4 & 23.0 & 26.3 \\
15.0 & 22.9 & 26.6 & 23.2 & 26.6 \\
15.5 & 23.1 & 26.9 & 23.4 & 27.9 \\
16.0 & 23.3 & 27.1 & 23.6 & 27.4 \\
16.5 & 23.5 & 27.4 & 23.7 & 27.6 \\
17.0 & 23.7 & 27.6 & 23.8 & 27.8 \\
17.5 & 23.8 & 27.8 & 23.9 & 28.0 \\
18.0 & 24.0 & 28.0 & 24.0 & \\
\hline
\end{tabular}

BMI, body mass index. BMI = weight $/$ height $^{2}\left(\mathrm{~kg} / \mathrm{m}^{2}\right)$.

\section{Appendix C}

Table A3. Weekly consumption frequencies of free sugars in adolescents by DMFT groups (mean \pm S.D., times/week).

\begin{tabular}{|c|c|c|c|}
\hline Food Groups & $\begin{array}{c}\text { Total } \\
(n=1517)\end{array}$ & $\begin{array}{c}\mathrm{DMFT}=0 \\
(n=654)\end{array}$ & $\begin{array}{c}\text { DMFT } \geq 1 \\
(n=863)\end{array}$ \\
\hline SSBs $* *$ & $6.2 \pm 8.0$ & $5.5 \pm 7.1$ & $6.7 \pm 8.6$ \\
\hline Confections $* *$ & $1.7 \pm 3.4$ & $1.5 \pm 3.1$ & $1.9 \pm 3.6$ \\
\hline Flavored milk/yogurt ** & $2.4 \pm 3.7$ & $2.1 \pm 3.3$ & $2.6 \pm 4.0$ \\
\hline Preserved fruits $* *$ & $0.8 \pm 2.5$ & $0.7 \pm 2.0$ & $0.9 \pm 2.7$ \\
\hline Cakes or desserts * & $1.5 \pm 2.8$ & $1.4 \pm 2.5$ & $1.6 \pm 3.0$ \\
\hline Honey & $0.5 \pm 1.9$ & $0.4 \pm 1.3$ & $0.6 \pm 2.3$ \\
\hline Total *** & $13.1 \pm 14.5$ & $11.5 \pm 11.9$ & $14.4 \pm 16.0$ \\
\hline
\end{tabular}

\section{References}

1. Meier, T.; Deumelandt, P.; Christen, O.; Stangl, G.I.; Riedel, K.; Langer, M. Global Burden of Sugar-Related Dental Diseases in 168 Countries and Corresponding Health Care Costs. J. Dent. Res. 2017, 96, 845-854. [CrossRef]

2. World Health Organization. Guideline: Sugars Intake for Adults and Children; World Health Organization: Geneva, Switzerland, 2015.

3. $\quad$ Pitts, N.B.; Zero, D.T.; Marsh, P.D.; Ekstrand, K.; Weintraub, J.A.; Ramos-Gomez, F.; Tagami, J.; Twetman, S.; Tsakos, G.; Ismail, A. Dental caries. Nat. Rev. Dis. Primers 2017, 3, 17030. [CrossRef]

4. James, S.L.; Abate, D.; Abate, K.H.; Abay, S.M.; Abbafati, C.; Abbasi, N.; Abbastabar, H.; Abd-Allah, F.; Abdela, J.; Abdelalim, A.; et al. Global, regional, and national incidence, prevalence, and years lived with disability for 354 diseases and injuries for 195 countries and territories, 1990-2017: A systematic analysis for the Global Burden of Disease Study 2017. Lancet 2018, 392, 1789-1858. [CrossRef]

5. Feng, X. Oral health status of Chinese residents: Report of the fourth oral health epidemiological survey in China. In Proceedings of the 2018 18th Annual Meeting of Oral Preventive Medicine of Chinese Stomatological Association, Xi'an, China, 25 October 2018; p. 2.

6. Mathur, V.P.; Dhillon, J.K. Dental Caries: A Disease Which Needs Attention. Indian J. Pediatr. 2018, 85, 202-206. [CrossRef]

7. Moynihan, P. Sugars and Dental Caries: Evidence for Setting a Recommended Threshold for Intake. Adv. Nutr. 2016, 7, 149-156. [CrossRef]

8. Johnson, R.K.; Appel, L.J.; Brands, M.; Howard, B.V.; Lefevre, M.; Lustig, R.H.; Sacks, F.; Steffen, L.M.; Wylie-Rosett, J. Dietary sugars intake and cardiovascular health: A scientific statement from the American Heart Association. Circulation 2009, 120, 1011-1020. [CrossRef]

9. Wiseman, M. The second World Cancer Research Fund/American Institute for Cancer Research expert report. Food, nutrition, physical activity, and the prevention of cancer: A global perspective. Proc. Nutr. Soc. 2008, 67, 253-256. [CrossRef] [PubMed] 
10. Sheiham, A.; James, W.P. A reappraisal of the quantitative relationship between sugar intake and dental caries: The need for new criteria for developing goals for sugar intake. BMC Public Health 2014, 14, 863. [CrossRef] [PubMed]

11. Ng, S.W.; Ni Mhurchu, C.; Jebb, S.A.; Popkin, B.M. Patterns and trends of beverage consumption among children and adults in Great Britain, 1986-2009. Br. J. Nutr. 2012, 108, 536-551. [CrossRef] [PubMed]

12. Nelson, M.C.; Neumark-Sztainer, D.; Hannan, P.J.; Story, M. Five-year longitudinal and secular shifts in adolescent beverage intake: Findings from project EAT (Eating among Teens)-II. J. Am. Diet. Assoc. 2009, 109, 308-312. [CrossRef] [PubMed]

13. Yang, C.C.; Chiou, W.B. Substitution of healthy for unhealthy beverages among college students. A health-concerns and behavioral-economics perspective. Appetite 2010, 54, 512-516. [CrossRef] [PubMed]

14. Dennis, E.A.; Flack, K.D.; Davy, B.M. Beverage consumption and adult weight management: A review. Eat. Behav. 2009, 10, 237-246. [CrossRef]

15. Drewnowski, A.; Mennella, J.A.; Johnson, S.L.; Bellisle, F. Sweetness and food preference. J. Nutr. 2012, 142, 1142s-1148s. [CrossRef]

16. The, N.S.; Suchindran, C.; North, K.E.; Popkin, B.M.; Gordon-Larsen, P. Association of adolescent obesity with risk of severe obesity in adulthood. JAMA 2010, 304, 2042-2047. [CrossRef]

17. Bailey, R.L.; Fulgoni, V.L.; Cowan, A.E.; Gaine, P.C. Sources of Added Sugars in Young Children, Adolescents, and Adults with Low and High Intakes of Added Sugars. Nutrients 2018, 10, 102. [CrossRef] [PubMed]

18. Gibson, S.; Francis, L.; Newens, K.; Livingstone, B. Associations between free sugars and nutrient intakes among children and adolescents in the UK. Br. J. Nutr. 2016, 116, 1265-1274. [CrossRef] [PubMed]

19. Kim, S.; Park, S.; Lin, M. Permanent tooth loss and sugar-sweetened beverage intake in U.S. young adults. J. Public Health Dent. 2017, 77, 148-154. [CrossRef]

20. Moynihan, P.J.; Kelly, S.A. Effect on caries of restricting sugars intake: Systematic review to inform WHO guidelines. J. Dent. Res. 2014, 93, 8-18. [CrossRef] [PubMed]

21. Buyken, A.E.; Mitchell, P.; Ceriello, A.; Brand-Miller, J. Optimal dietary approaches for prevention of type 2 diabetes: A life-course perspective. Diabetologia 2010, 53, 406-418. [CrossRef]

22. Mahoney, L.T.; Burns, T.L.; Stanford, W.; Thompson, B.H.; Witt, J.D.; Rost, C.A.; Lauer, R.M. Coronary risk factors measured in childhood and young adult life are associated with coronary artery calcification in young adults: The Muscatine Study. J. Am. Coll. Cardiol. 1996, 27, 277-284. [CrossRef]

23. Yu, L.; Jiang, Y.; Chu, Z.; Wang, K.; Zhuang, M.; Xiao, P.; Wang, L. Analysis of the soft drink consumption and free sugar intake in 6 14-year-old children in Shandong, China. Chin. J. Child Health Care 2017, 25, 1166-1169.

24. Liu, S. Analysis on Status and Influence Factors of Carbonated Beverage Consumption in Nine Provinces of Chinese Population; MPH, Chinese Center for Disease Control and Prevention: Beijing, China, 2016.

25. Zhu, Z.; He, Y.; Wang, Z.; He, X.; Zang, J.; Guo, C.; Jia, X.; Ren, Y.; Shan, C.; Sun, J.; et al. The associations between sugar-sweetened beverage intake and cardiometabolic risks in Chinese children and adolescents. Pediatr. Obes. 2020, 15, e12634. [CrossRef] [PubMed]

26. National Health and Family Planning Commission of the People's Republic of China (Ed.) Screening for Overweight and Obesity among School-Age Children and Adolescents; WS/T 586-2018; National Health and Family Planning Commission of the People's Republic of China: Beijing, China, 2018.

27. World Health Organization. Oral Health Surveys: Basic Methods-5th Edition 2013. Available online: https://apps.who.int/iris/ handle/10665/97035 (accessed on 18 January 2021).

28. The Chinese Nutrition Society. The Food Guide Pagoda for Chinese Residents; The Chinese Nutrition Society: Beijing, China, 2016.

29. Azaïs-Braesco, V.; Sluik, D.; Maillot, M.; Kok, F.; Moreno, L.A. A review of total \& added sugar intakes and dietary sources in Europe. Nutr. J. 2017, 16, 6. [CrossRef]

30. Perrar, I.; Schadow, A.M.; Schmitting, S.; Buyken, A.E.; Alexy, U. Time and Age Trends in Free Sugar Intake from Food Groups among Children and Adolescents between 1985 and 2016. Nutrients 2019, 12, 20. [CrossRef]

31. Liu, S. The Status and Change of Sugary Food Consumption and Its Relationship with Overweight and Obesity in Chinese Residents during 2002-2012; Chinese Center for Disease Control and Prevention: Beijing, China, 2016.

32. Tian, S.; Xin, P.; Wang, Z.; Li, W.; Xue, X.; Zhang, S.; Wang, D.; Wang, G. Association between added sugars and salt intake with blood pressure in Tianjin residents. Chin. J. Dis. Control Prev. 2017, 21, 974-978.

33. Erickson, J.; Slavin, J. Total, added, and free sugars: Are restrictive guidelines science-based or achievable? Nutrients 2015, 7, 2866-2878. [CrossRef]

34. Desbouys, L.; De Ridder, K.; Rouche, M.; Castetbon, K. Food Consumption in Adolescents and Young Adults: Age-Specific Socio-Economic and Cultural Disparities (Belgian Food Consumption Survey 2014). Nutrients 2019, 11, 1520. [CrossRef]

35. Newens, K.J.; Walton, J. A review of sugar consumption from nationally representative dietary surveys across the world. J. Hum. Nutr. Diet. Off. J. Br. Diet. Assoc. 2016, 29, 225-240. [CrossRef] [PubMed]

36. Park, S.; Thompson, F.E.; McGuire, L.C.; Pan, L.; Galuska, D.A.; Blanck, H.M. Sociodemographic and Behavioral Factors Associated with Added Sugars Intake among US Adults. J. Acad. Nutr. Diet. 2016, 116, 1589-1598. [CrossRef] [PubMed]

37. Bogart, L.M.; Elliott, M.N.; Ober, A.J.; Klein, D.J.; Hawes-Dawson, J.; Cowgill, B.O.; Uyeda, K.; Schuster, M.A. Home Sweet Home: Parent and Home Environmental Factors in Adolescent Consumption of Sugar-Sweetened Beverages. Acad. Pediatr. 2017, 17, 529-536. [CrossRef] 
38. Graffe, M.I.M.; Pala, V.; De Henauw, S.; Eiben, G.; Hadjigeorgiou, C.; Iacoviello, L.; Intemann, T.; Jilani, H.; Molnar, D.; Russo, P.; et al. Dietary sources of free sugars in the diet of European children: The IDEFICS Study. Eur. J. Nutr. 2020, 59, 979-989. [CrossRef] [PubMed]

39. Lei, L.; Rangan, A.; Flood, V.M.; Louie, J.C.Y. Dietary intake and food sources of added sugar in the Australian population. Br. J. Nutr. 2016, 115, 868-877. [CrossRef]

40. Sluik, D.; van Lee, L.; Engelen, A.I.; Feskens, E.J. Total, Free, and Added Sugar Consumption and Adherence to Guidelines: The Dutch National Food Consumption Survey 2007-2010. Nutrients 2016, 8, 70. [CrossRef]

41. Ruiz, E.; Rodriguez, P.; Valero, T.; Ávila, J.M.; Aranceta-Bartrina, J.; Gil, Á.; González-Gross, M.; Ortega, R.M.; Serra-Majem, L.; Varela-Moreiras, G. Dietary Intake of Individual (Free and Intrinsic) Sugars and Food Sources in the Spanish Population: Findings from the ANIBES Study. Nutrients 2017, 9, 275. [CrossRef] [PubMed]

42. Farajian, P.; Risvas, G.; Panagiotakos, D.B.; Zampelas, A. Food sources of free sugars in children's diet and identification of lifestyle patterns associated with free sugars intake: The GRECO (Greek Childhood Obesity) study. Public Health Nutr. 2016, 19, 2326-2335. [CrossRef] [PubMed]

43. Hou, L. Analysis of Sugar Content in Prepackaged Foods and Its Application in Population Sugar Intake Assessment in China; Chinese Center for Disease Control and Prevention: Beijing, China, 2017.

44. Mazarello Paes, V.; Hesketh, K.; O’Malley, C.; Moore, H.; Summerbell, C.; Griffin, S.; van Sluijs, E.M.; Ong, K.K.; Lakshman, R. Determinants of sugar-sweetened beverage consumption in young children: A systematic review. Obes. Rev. J. Int. Assoc. Study Obes. 2015, 16, 903-913. [CrossRef]

45. Flieh, S.M.; Moreno, L.A.; Miguel-Berges, M.L.; Stehle, P.; Marcos, A.; Molnár, D.; Widhalm, K.; Béghin, L.; De Henauw, S.; Kafatos, A.; et al. Free Sugar Consumption and Obesity in European Adolescents: The HELENA Study. Nutrients 2020, $12,3747$. [CrossRef] [PubMed]

46. Ha, K.; Chung, S.; Lee, H.-S.; Kim, C.-I.; Joung, H.; Paik, H.-Y.; Song, Y. Association of Dietary Sugars and Sugar-Sweetened Beverage Intake with Obesity in Korean Children and Adolescents. Nutrients 2016, 8, 31. [CrossRef] [PubMed]

47. Jomaa, L.; Hamamji, S.; Kharroubi, S.; Diab-El-Harakeh, M.; Al Zahraa Chokor, F.; Nasreddine, L. Dietary intakes, sources, and determinants of free sugars amongst Lebanese children and adolescents: Findings from two national surveys. Eur. J. Nutr. 2021. [CrossRef]

48. Malik, V.S.; Pan, A.; Willett, W.C.; Hu, F.B. Sugar-sweetened beverages and weight gain in children and adults: A systematic review and meta-analysis. Am. J. Clin. Nutr. 2013, 98, 1084-1102. [CrossRef]

49. Ma, C. Forecast of development trend of beverage industry in 2017. China's Food 2016, 22, 74-75.

50. Wang, H. The development trend of food and beverage market under consumption upgrade. Label Technol. 2019, 4, 12-16.

51. Zeng, Y. The Study of Prevalence Status and Related Factors of Dental Caries and Periodontal Health among 12-15-Year-Olds People in Jiangxi Province; Nanchang University: Nanchang, China, 2019.

52. Hu, J.; Jiang, W.; Lin, X.; Zhu, H.; Zhou, N.; Chen, Y.; Wu, W.; Zhang, D.; Chen, H. Dental Caries Status and Caries Risk Factors in Students Ages 12-14 Years in Zhejiang, China. Med. Sci. Monit. 2018, 24, 3670-3678. [CrossRef] [PubMed]

53. Cai, T. An Investigation and Analysis of Oral Health Status and Risk Factors of Caries for Middle School Students in Chongqing; Chongqing Medical University: Chongqing, China, 2018.

54. Ji, Y.; Wang, Z.; Yang, B.; Sun, J.; He, J. Analysis of permanent tooth caries and its influencing factors in 12-year-old left-behind children in rural areas of Henan province. Chin. J. Sch. Health 2015, 36, 1906-1908.

55. Fiorillo, L. Oral Health: The First Step to Well-Being. Medicina 2019, 55, 676. [CrossRef]

56. Yip, W.; Fu, H.; Chen, A.T.; Zhai, T.; Jian, W.; Xu, R.; Pan, J.; Hu, M.; Zhou, Z.; Chen, Q.; et al. 10 years of health-care reform in China: Progress and gaps in Universal Health Coverage. Lancet 2019, 394, 1192-1204. [CrossRef]

57. Moynihan, P.; Petersen, P.E. Diet, nutrition and the prevention of dental diseases. Public Health Nutr. 2004, 7, 201-226. [CrossRef]

58. Sheiham, A.; James, W.P. A new understanding of the relationship between sugars, dental caries and fluoride use: Implications for limits on sugars consumption. Public Health Nutr. 2014, 17, 2176-2184. [CrossRef]

59. Van Loveren, C. Sugar Restriction for Caries Prevention: Amount and Frequency. Which Is More Important? Caries Res. 2019, 53, 168-175. [CrossRef]

60. Yang, Q.; Zhang, Z.; Gregg, E.W.; Flanders, W.D.; Merritt, R.; Hu, F.B. Added sugar intake and cardiovascular diseases mortality among US adults. JAMA Intern. Med. 2014, 174, 516-524. [CrossRef]

61. Gibson, S. Sugar-sweetened soft drinks and obesity: A systematic review of the evidence from observational studies and interventions. Nutr. Res. Rev. 2008, 21, 134-147. [CrossRef] [PubMed]

62. Gomes, D.; Luque, V.; Xhonneux, A.; Verduci, E.; Socha, P.; Koletzko, B.; Berger, U.; Grote, V. A simple method for identification of misreporting of energy intake from infancy to school age: Results from a longitudinal study. Clin. Nutr. 2018, 37, 1053-1060. [CrossRef]

63. Sahoo, K.; Sahoo, B.; Choudhury, A.K.; Sofi, N.Y.; Kumar, R.; Bhadoria, A.S. Childhood obesity: Causes and consequences. J. Fam. Med. Prim. Care 2015, 4, 187-192. [CrossRef]

64. Kopycka-Kedzierawski, D.T.; Auinger, P.; Billings, R.J.; Weitzman, M. Caries status and overweight in 2- to 18-year-old US children: Findings from national surveys. Community Dent. Oral Epidemiol. 2008, 36, 157-167. [CrossRef] 
65. Benzian, H.; Monse, B.; Heinrich-Weltzien, R.; Hobdell, M.; Mulder, J.; van Palenstein Helderman, W. Untreated severe dental decay: A neglected determinant of low Body Mass Index in 12-year-old Filipino children. BMC Public Health 2011, 11, 558. [CrossRef]

66. Subramaniam, P.; Singh, D. Association of age specific body mass index, dental caries and socioeconomic status of children and adolescents. J. Clin. Pediatr. Dent. 2011, 36, 175-179. [CrossRef]

67. Trikaliotis, A.; Boka, V.; Kotsanos, N.; Karagiannis, V.; Hassapidou, M. Short communication: Dmfs and BMI in preschool Greek children. An epidemiological study. Eur. Arch. Paediatr. Dent. 2011, 12, 176-178. [CrossRef] [PubMed]

68. Honne, T.; Pentapati, K.; Kumar, N.; Acharya, S. Relationship between obesity/overweight status, sugar consumption and dental caries among adolescents in South India. Int. J. Dent. Hyg. 2012, 10, 240-244. [CrossRef]

69. Li, W.; Hussein Musa, T.; Gao, R.; Li, X.S.; Wang, W.X.; Hong, L.; Wei, P.M. Association between BMI and Dental Caries among School Children and Adolescents in Jiangsu Province, China. Biomed. Environ. Sci. 2017, 30, 758-761. [CrossRef] [PubMed]

70. Parnell, W.; Wilson, N.; Alexander, D.; Wohlers, M.; Williden, M.; Mann, J.; Gray, A. Exploring the relationship between sugars and obesity. Public Health Nutr. 2008, 11, 860-866. [CrossRef] [PubMed]

71. Gibson, S.A. Are high-fat, high-sugar foods and diets conducive to obesity? Int. J. Food Sci. Nutr. 1996, 47, 405-415. [CrossRef] [PubMed]

72. Drewnowski, A.; Brunzell, J.D.; Sande, K.; Iverius, P.H.; Greenwood, M.R. Sweet tooth reconsidered: Taste responsiveness in human obesity. Physiol. Behav. 1985, 35, 617-622. [CrossRef] 